\title{
1. Introduction: what would a water-sustainable city look like?
}

This book explores the dynamic relationship between cities and water. It is the product of insights acquired through our research on the PIRE project, which is focused on developing and deploying low-energy options for improving water productivity while taking into account the environmental and social values of water. It is designed for advanced undergraduate and graduate students, as well as for water professionals, policymakers, and members of the public who aspire to a more in-depth understanding of contemporary water issues.

This book focuses on two subjects. First, how are fast-growing cities, both in developing and developed countries, impacting freshwater availability and quality in their region of influence? Second, what tools for analyzing the environmental and social impacts of urban water consumption - and for choosing approaches and policies for addressing various threats to freshwater management - are available? As noted in the Preface, our goal is to help cities manage water while confronting the challenges of climate change, maintaining ecosystem form and function, and reducing the water and energy footprint of cities so as to put them on a more sustainable path that quenches our thirst for water while preserving ecological health and societal well-being.

Human overuse of water resources has placed enormous pressures on freshwater availability. Cities - especially large ones - exacerbate these problems in three distinct ways. First, they are often located some distance from the water sources needed by their populations. In the past, at least, this has compelled them to build new infrastructure to divert water from increasingly distant outlying rural areas, thus disrupting their social fabric and their environment. More recently, cities have been turning to local and lower-quality sources of water, largely because the distant high quality sources have been tapped out. This is not a new problem: as we will show in Chapter 2, it is as old as antiquity.

Second, increasing urbanization due to population growth, economic change and sprawl places huge burdens upon the institutions, as well as the infrastructure, that deliver and treat urban water, especially in developing countries where these challenges are compounded by rapid growth, weak 
institutions, and insufficient funding capacity. While greater concentration of people in cities may lower unit costs for many forms of water infrastructure, the need to expand water supply and treatment networks over vast areas may increase the likelihood of distribution system leaks and other failures (United Nations Human Settlements Programme, 2011).

And third, the spatial "footprint" caused by sprawling horizontal urban development and annexation imposes numerous water-related problems. A few of the most important of these include paving of city streets and commercial districts (which contributes to pollutant runoff and diminished groundwater recharge); consumption of water for parks and outdoor residential use (increasing evapotranspiration and taxing local supplies); increased urban "hot spots" due to the alteration of land cover; and, urban waste discharges that affect local to global biogeochemical cycles and climate (Grimm et al., 2008). While cities themselves present numerous water problems, they also harbor many of the solutions to the sustainability challenges of an urbanizing world.

This book will focus on innovative solutions that foster water conservation, repurposing of water, wastewater reuse, and more generally: local treatment techniques that require less energy, rely on natural processes, and generate environmental value (such as constructed wetlands), as opposed to established practices such as long-distance diversion and large, centralized, energy intensive treatment and distribution approaches. After providing an overview of the complex water challenges facing fast-growing and established urban areas if we stay the course, we will strive to understand how cities have tackled their water challenges based on examples from the past as well as the present.

\section{THE FUTURE OF CITIES AND WATER: THE PRESENT AS PROLOGUE}

What might cities of the future look like if they could use water more sustainably - in ways that protect environmental quality, promote economic development, and foster just and equitable resource allocation and management? This chapter provides an overview of some of the principles and practices that might characterize such a future city, particularly drawing upon methods to regenerate, conserve, and substitute for freshwater, as well as impediments to adopting these methods - especially as seen in Australia and the U.S. A good place to begin might be to examine cities and their water uses in the present.

As of 2016, more than half of the world's population lives in cities - some 3.5 billion souls. Putting this into further perspective, at the current rate of 
population growth, the world's urban population is growing by some two people every second. And, in developing countries, this growth rate is the equivalent of some five million new urban dwellers every month. Moreover, while there are many reasons people choose to live in cities, even in less developed nations where water quality tends to be sub-standard (a topic we take up later in the book), in general, water conditions in cities tend to be far better than in non-urban areas. According to the United Nations, as of 2010, 96 percent of the world's urban residents had access to improved sources of drinking (as compared to 81 percent of those living in rural areas). For sanitation facilities, the disparities are even more profound: 79 percent of the world's urban dwellers had access to improved sanitation facilities while only 47 percent of rural dwellers did (Swyngedouw, 2007).

"Megacities" composed of tens-of-millions of people comprise a phenomenon that is especially acute in developing countries. Some 80 percent of the world's city dwellers live in developing countries. While spanning various levels of modernity, nevertheless, more than two-thirds of the world's urban residents live in cities in Africa, Asia, and Latin America, where development lags behind most of Europe, North America, and other industrialized countries. Since 1950, the urban populace of these regions has grown five-fold, while in Africa and Asia alone, urban populations are expected to double by 2030 (Satterthwaite, 2000).

Perhaps more compelling than these raw statistics, however, is that despite the progress made in improving water provisioning and sanitation in the world's cities, these services face a race against time and place. Over the next 35 years or so, the world's urban population is expected to increase from some 4 billion to 6.3 billion by 2050 - a higher rate of growth (36 percent) than the overall projected rate of the world's population (26 percent) during this period (UN Water, 2014). Most of this growth will occur in cities in the poorest of the world's nations, where densely populated slums replete with sub-standard housing already pose enormous challenges regarding access to safe water and sanitation.

In part because of the rapid rate of urban growth in the poorest nations of the world, between 2000 and 2008 urban areas worldwide witnessed a deterioration in both water and sanitation coverage, with access to sanitary toilets decreasing by some 20 percent (UN Water, 2014). Moreover, urban settlement is the main source of point-source water discharges such as raw sewage.

The same United Nations reports that cite these dire statistics also pin their hopes for improvement on the very kinds of initiatives that we identify as characteristic of a water-sensitive city - a reliance not just upon sophisticated and centrally managed technologies, but on exploitation of comprehensive urban water planning, investment and associated operations in the cities of the future. In essence, developing countries may be 
able to "skip" the mistakes made by more developed nations and develop distributed and eco-sensitive approaches to stormwater management and other approaches more quickly than developed countries.

With this challenge as context, our research through PIRE, and that of other investigators, defines a water-sustainable city as a place that imposes minimal adverse impact on water resources; pursues options for the delivery, treatment, use, and management of water that embrace a positive water-energy nexus - that is, high water productivity with low energy use (and thus, a low carbon footprint); and embraces these initiatives as parts of a "holistic framework" embracing all aspects of the water system in a city (Howe et al., 2011). Such holistic development revolves around adoption of three principal sets of options (Figure 1.1) that include low-energy approaches for substituting, regenerating, and conserving freshwater.

Substitution is the use of lower-quality freshwater for urban uses such as industrial cooling and landscape irrigation. At the household level, it could encompass watering gardens with rainwater from a tank, as well as flushing toilets and washing laundry with treated stormwater effluent from a rain garden or similar structure. Regeneration involves deriving high-quality water from lower-quality water, including wastewater and stormwater through direct or indirect (for example, treatment and groundwater replenishment) methods. As shown, a waste stabilization pond (WSP) can transform household sewage into high-quality water for irrigating an orchard. Finally, conservation includes reductions in use through water-saving appliances (for example, drip irrigation, dual-flush toilets, low-flow shower roses, front-loading clothes washers), as well as by use of innovative rate-structures, and even water-less toilets and urinals - as well as vigilant repair of leaks in distribution systems. Related infrastructure includes conventional drinking water treatment plant (DWTP); wastewater treatment plant (WWTP); and river diversion (supplying the orchard).

Keys to these innovations' acceptability and likelihood of adoption include, first, changes in public confidence and perceived competence in those responsible for managing these innovations brought about through public education to hasten trust (Po et al., 2005). In effect, cities of the future must undergo a "paradigm shift" to overcome bureaucratic inertia, developer concerns with returns-on-investment, tendencies toward fragmented urban planning, and resistance to public-private partnerships in water governance decisions (Saha and Paterson, 2008; Van de Meene et al., 2011). Second, policy - particularly regulatory - change also will be needed to establish scientifically supportable risk-criteria; enhance public confidence in water reuse; and eliminate concerns about inconsistent standards between different jurisdictions (Nellor and Larson, 2010). Third, as is graphically shown in Figure 1.1, these innovations are best 


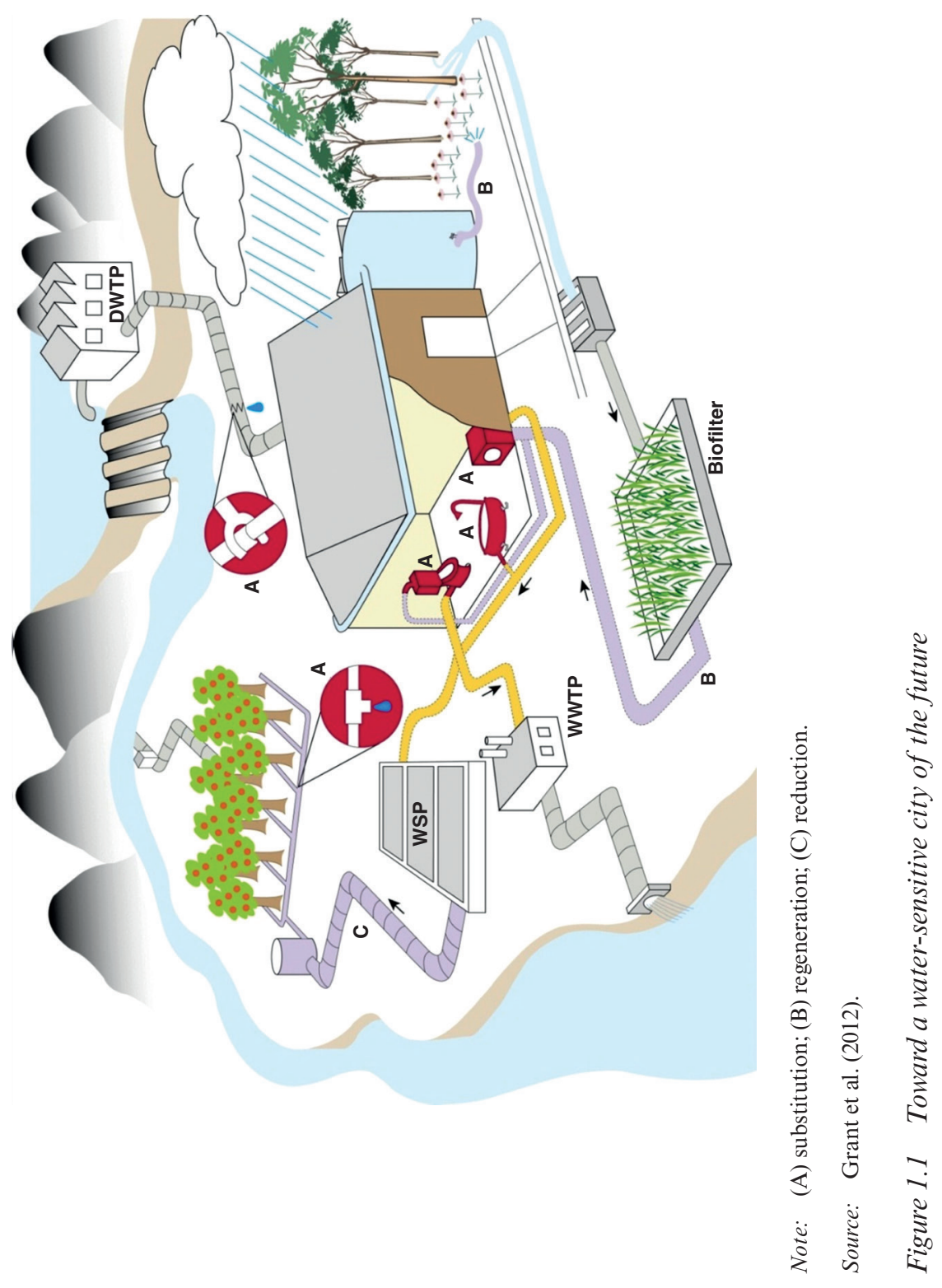


introduced as distributed household or neighborhood-level improvements, or "add-ons" to existing water infrastructure. This makes them more practical and adaptive in their implementation because they are not being marketed as replacements for traditional infrastructure, which has the confidence of the public due to its proven reliability.

But why is a water-sensitive city really needed? Why won't traditional approaches do? To understand the justification for a water-sensitive city, we have to consider two other factors: climate variability/climate change as a set of variables affecting water availability, particularly in regions already water stressed; and the quest for meeting future water needs in a manner that is environmentally sustainable - a demand that has become especially tractable in the world's most highly advanced economies.

\section{CLIMATE CHANGE, WATER AND CITIES}

In recent years a strong consensus has grown among climate scientists, hydrologists, and others who contend that continued carbon dioxide and methane emissions will alter the climate in various ways. Global average temperatures will rise, for example, and dramatic changes in precipitation could adversely affect the world's freshwater supply. Rainfall intensity may increase in some regions and decline in others, while the seasonal balance between snow and rain might also shift, affecting local economies. Higher temperatures could increase evaporation and transpiration - the rate at which plants give up moisture to the atmosphere - while reduced soil moisture affects farming. Over longer time periods, shifts in vegetation cover over entire regions - from forest to grassland or grassland to desert - may occur. Accelerated melting of polar and glacial ice, another probable result of climate change, would lead to greater sea-level rise and saltwater intrusion into coastal estuaries, affecting fisheries and threatening urban drinking water supplies, and there are several positive feedback loops that could accelerate and exacerbate climate change, for example release of methane to the atmosphere as ice sheets and permafrost melt (IPCC, 2014).

Many scientists believe these changes are not only likely scenarios, but that current protracted drought in some regions, and unprecedented flooding in others, are harbingers of worse to come. While debate over whether and to what extent any given climatic event may be attributable to global climate change is far from settled, there is growing agreement that the increasing frequency of water-related extreme climate events is probably the result of human-induced climate change, including periods of more frequent and severe drought (Gleick and Heberger, 2012: 1-14; Griffin and Anchukaltis, 2014). 
Table 1.1 Some adaptation options for freshwater

\begin{tabular}{|c|c|}
\hline Supply side & Demand side \\
\hline $\begin{array}{l}\text { Prospecting and } \\
\text { extraction of } \\
\text { groundwater }\end{array}$ & $\begin{array}{l}\text { Improvement of water-use efficiency by recycling } \\
\text { water }\end{array}$ \\
\hline $\begin{array}{l}\text { Increasing storage } \\
\text { capacity by building } \\
\text { reservoirs and dams }\end{array}$ & $\begin{array}{l}\text { Reduction in water demand for irrigation by changing } \\
\text { the cropping calendar, crop mix, irrigation method and } \\
\text { area planted }\end{array}$ \\
\hline $\begin{array}{l}\text { Desalination of } \\
\text { seawater }\end{array}$ & $\begin{array}{l}\text { Reduction in water demand for irrigation by importing } \\
\text { agricultural products, i.e., virtual water }\end{array}$ \\
\hline $\begin{array}{l}\text { Expansion of rainwater } \\
\text { storage }\end{array}$ & $\begin{array}{l}\text { Promotion of indigenous practices for sustainable } \\
\text { water use }\end{array}$ \\
\hline $\begin{array}{l}\text { Removal of invasive } \\
\text { non-native vegetation } \\
\text { from riparian areas }\end{array}$ & $\begin{array}{l}\text { Expanded use of water markets to reallocate water to } \\
\text { highly valued uses }\end{array}$ \\
\hline Water transfer & $\begin{array}{l}\text { Expanded use of economic incentives including } \\
\text { metering and pricing to encourage water conservation }\end{array}$ \\
\hline
\end{tabular}

Source: IPCC (2007), Table 3.5. Also, see IPCC (2014), p. 27.

What does this portend for cities? Perhaps most critically, it means a growing reliance upon adaptation measures that can enhance our ability to manage water supply while hopefully attenuating urban water demands in the face of climate uncertainty. This requires imaginative management as well as good science, and it further depends on the ability to translate knowledge into language useful to decision-makers and the public. Moreover, activities undertaken for reasons other than climate change will be needed - what are sometimes referred to as "no regrets" strategies that have numerous benefits, such as the ability to accommodate population growth and growing demands - even if temperature or precipitation does not vary significantly over time (see Table 1.1).

As regards the aspiration to meet growing urban water needs in an environmentally sustainable manner, concerns with climate change and population growth have definitely affected the inclination of water resource planners and others to embrace new methods for providing water supply which avert - whenever possible - needs for large-scale, centralized and expensive to maintain infrastructure. Alternatively, newer, more resilient, and more "self-reliant" methods have arisen - self-reliant in the sense that cities can obtain reliable water supplies by better harvesting of local sources without resort to distant diversions or transfers of water across basins. Such remedies as we shall see include the harvesting, storage, 
and reuse of stormwater; the biofiltration of mildly polluted runoff; and the reuse/recycling of various grades of wastewater for different purposes.

\section{OTHER MOTIVES FOR A WATER-SUSTAINABLE CITY: EMBRACING GROWTH, ASSURING LIVABILITY}

While concern over climate change is a major impetus for adopting sustainability, it is by no means the only motivation. The International Water Association in its 2013 Cities of the Future report suggests adoption of these approaches should be undertaken in order to ensure that cities are both livable and resilient in the face of a growing urban population. Moreover, it suggests, these approaches should be adopted through methods that: engage various members of the public; ensure collaborative implementation; promote localized and adaptive solutions that can also be disseminated to other urban sectors; and promote "water literacy" among the urban public. Finally, IWA recommends that "all water is good water" and that future efficiency must "match quality to use" (International Water Association, 2013).

The IWA approach requires inter-disciplinary methods to be applied to understanding - and solving - urban water problems. Similar conclusions and recommendations have been reached by the European Union, and UNESCO (whose recent efforts on behalf of water-sustainable "cities of the future" promote interdisciplinary research from a long-term perspective). The International Water Association's "cities of the future" program, which connects water professionals from over 130 countries on many of these issues, and which recently issued a Declaration on cities of the future, has no doubt abetted this global diffusion of ideas (Howe et al., 2011: 30; UNESCO-IHE, 2011; International Water Association, 2013).

Our discussion in the following chapters weighs technological obstacles that must be overcome, as well as the cultural, social, economic, political, and legal hurdles that must be surmounted in order to achieve these goals. A theme of this book is that integrated urban water management is an approach to water that considers the management of demand a source of water, as much the augmentation of supply - and that water quality and quantity must be conjointly managed.

One major conclusion we will draw throughout this book is that water should be managed in cities to achieve - as close as possible - a "closed loop" system. In other words, what we should aspire to is not once-through water supply, stormwater, and/or wastewater streams, but a renewable, reusable resource (see Figure 1.2). How we can approximate this aspiration through better applying our knowledge to the realities of city life is the 


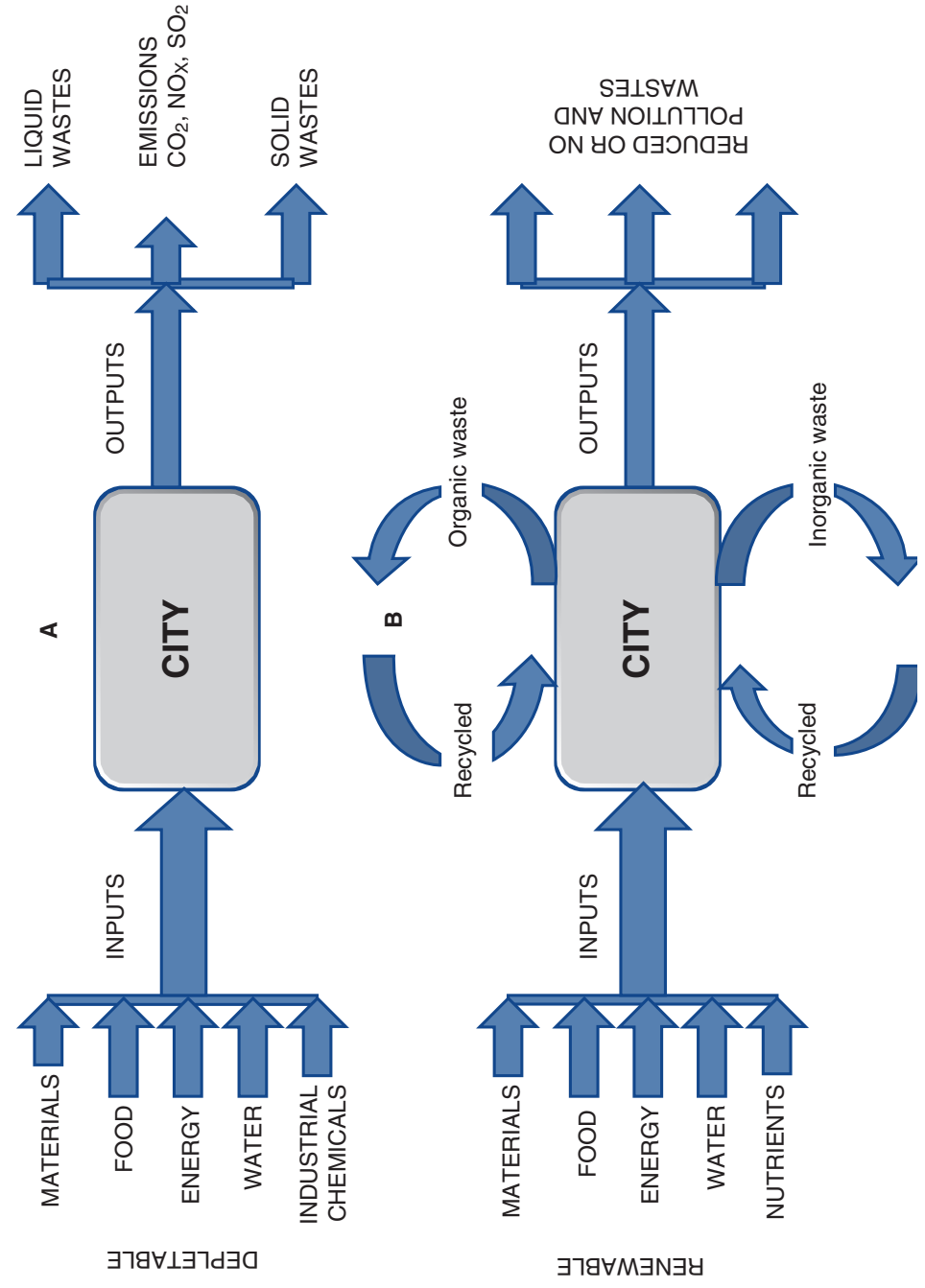

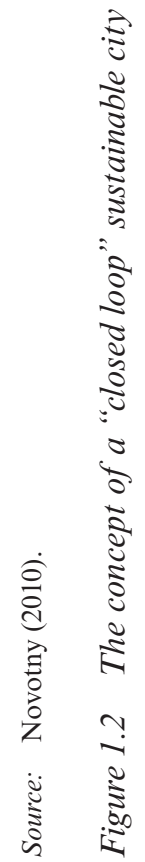


subject of the following chapters. We begin, in Chapter 2, by discussing how cities have historically thought about these issues in different times and places.

In looking toward policy solutions, we will discuss two emerging issues. First, the precise urban form that growing megacities take can have a profound influence on water use and water supply impacts. For instance, sprawling horizontal urban development imposes numerous problems, including paving of streets and commercial districts, and diminishing of groundwater recharge (see Chapters 5, 7, and 8, especially). And second, many megacities have learned - in sometimes impromptu and improvisational ways - how to mitigate the pressures of growth and climate variability on water stress (for example, Chapters 3,4 , and 7 ).

Improvisations include better managing water demands, coupled with compensatory efforts for low-income groups who can least afford these innovations. We discuss how these steps can lead to reductions in per capita water use and forestall the need for additional supplies in developedcountry cities as diverse as Los Angeles, New York, Tokyo, and Melbourne. While not a megacity, the latter's environmental footprint upon its surrounding region - particularly in light of Australia's recent Millennium Drought - is comparable to that of one. 